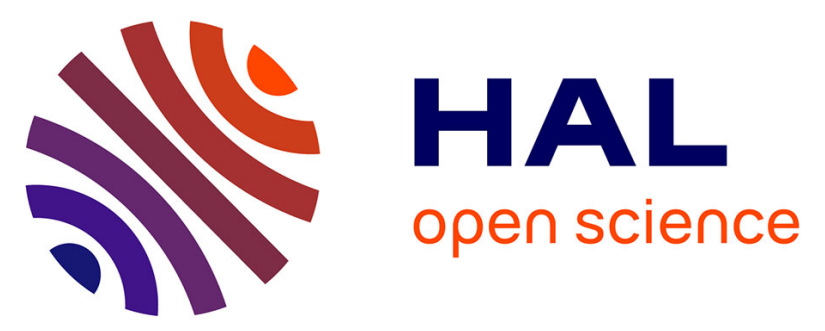

\title{
Improvement of kinetics, yield, and colloidal stability of biogenic gold nanoparticles using living cells of Euglena gracilis microalga
}

Si Amar Dahoumane, Claude Yéprémian, Chakib Djédiat, Alain Couté, Fernand Fiévet, Thibaud Coradin, Roberta Brayner

\section{To cite this version:}

Si Amar Dahoumane, Claude Yéprémian, Chakib Djédiat, Alain Couté, Fernand Fiévet, et al.. Improvement of kinetics, yield, and colloidal stability of biogenic gold nanoparticles using living cells of Euglena gracilis microalga. Journal of Nanoparticle Research, 2016, 18 (3), pp.79. 10.1007/s11051016-3378-1 . hal-01288636

\section{HAL Id: hal-01288636 https://hal.sorbonne-universite.fr/hal-01288636}

Submitted on 15 Mar 2016

HAL is a multi-disciplinary open access archive for the deposit and dissemination of scientific research documents, whether they are published or not. The documents may come from teaching and research institutions in France or abroad, or from public or private research centers.
L'archive ouverte pluridisciplinaire HAL, est destinée au dépôt et à la diffusion de documents scientifiques de niveau recherche, publiés ou non, émanant des établissements d'enseignement et de recherche français ou étrangers, des laboratoires publics ou privés. 


\section{Improvement of kinetics, yield and colloidal stability of biogenic gold nanoparticles using living cells of Euglena gracilis microalga}

Si Amar Dahoumane ${ }^{1,2 *}$, Claude Yéprémian ${ }^{3}$, Chakib Djédiat ${ }^{3}$, Alain Couté $^{3}$, Fernand Fiévet ${ }^{1}$, Thibaud Coradin $^{4 *}$, Roberta Brayner ${ }^{1 *}$

${ }^{1}$ Paris-Diderot Univ., Sorbonne Paris Cité, Interfaces, Traitements, Organisation et Dynamique des Systèmes (ITODYS), UMR 7086, CNRS, 15 rue Jean de Baïf, F-75205 Paris Cedex 13, France.

sa.dahoumane@gmail.com (SAD), roberta.brayner@univ-paris-diderot.fr (RB)

${ }^{2}$ Yachay Tech Univ., School of Life Sciences and Biotechnology, Hacienda San José, San Miguel de Urcuquí, Ecuador.

${ }^{3}$ Muséum National d'Histoire Naturelle, Département RDDM, UMR 7245, Unité MCAM, 57 rue Cuvier, case 39, 57 rue Cuvier, F-75005 Paris, France.

${ }^{4}$ UPMC - Paris 06, CNRS, Chimie de la Matière Condensée de Paris, Collège de France, 11 place Marcellin Berthelot, F-75005 Paris, France.

thibaud.coradin@upmc.fr (TC) 


\begin{abstract}
Recent years have witnessed a boom in the biosynthesis of a large variety of nanomaterials using different biological resources among which algae-based entities have been gaining much more attention within the community of material scientists worldwide. In our previously published findings, we explored some factors that governed the biofabrication of gold nanoparticles using living cultures of microalgae, such as the utilized microalgal genera, the phylum they belong to and the impact of tetrachloroauric acid concentrations on the ability of these strains to perform the biosynthesis of gold nanoparticles once in contact with these cations. As a follow-up, we present in this paper an improvement of the features of bioproduced gold colloids using living cells of Euglena gracilis microalga when this species is grown under either mixotrophic or autotrophic conditions, i.e., exposed to light and grown in an organic carbon enriched culture medium vs. under autotrophic conditions. As an outcome to this alteration, the growth rate of this photosynthetic microorganism is multiplied 7-8 times when grown under mixotrophic conditions compared to autotrophic ones. Therefore, the yield, the kinetics and the colloidal stability of biosynthesized gold nanoparticles are dramatically enhanced. Moreover, the shape and the size of the as-produced nano-objects via this biological method are affected. In addition to round-shaped gold nanoparticles, particular shapes, such as triangles and hexagons, appear. These findings add up to the amassed knowledge towards the design of photobioreactors for the scalable and sustainable production of nanomaterials.
\end{abstract}

Key-words: Biotechnology, Euglena gracilis, gold nanoparticles, biosynthesis, colloidal stability, kinetics, yield. 


\section{Introduction}

Nanomaterial biosynthesis refers to the use of biological resources, such as bacteria, fungi, plants and biomolecules, as biocatalysts for the production of inorganic nano-structured objects (Castro et al. 2014; Jeffryes et al. 2014; Klaus-Joerger et al. 2001; Pantidos and Horsfall 2014). Generally, these biocatalysts act, at the same time, as reducing and capping agents. After a slow start, the utilization of algal resources for the bioproduction of various nanomaterials has witnessed an outstanding boom. The paper by Liu et al. (2005) was the first paper to ever report on the biosynthesis of gold nanoparticles using aqueous extracts of the brown macroalga, or seaweed, Sargassum sp. (Liu et al. 2005). This pioneering work demonstrated that, by tuning the experimental parameters, such as the $\mathrm{pH}$, reaction time, the temperature and the amount of used biomass, it is possible to tailor the features of the so-produced gold nanoparticles and obtain, under certain conditions, triangular or hexagonal nanoplates.

Several methodologies using algae-based bioactive materials have been devised for the biosynthesis of a large range of nanomaterials starting from the corresponding salts. For instance, the algal biomass can be under the form of an aqueous extract or broth, collected intact cells of microalgae which are then suspended in double distilled water $\left(\mathrm{ddH}_{2} \mathrm{O}\right)$, living cells of microalgae maintained under their normal culturing conditions or purified proteins from algal species. The aqueous extract is generally collected from macroalgae, especially brown, red and green ones, and used as a mediator for the biosynthesis of nanomaterials made of gold (Castro et al. 2013; Mata et al. 2009; Rajeshkumar et al. 2013; Sharma et al. 2014), silver (Govindaraju et al. 2009; Kannan et al. 2013a; Kannan et al. 2013b; Kumar et al. 2013; Kumar et al. 2012a; Kumar et al. 2012b), platinum, palladium (Momeni and Nabipour 2015), iron oxide (Mahdavi et al. 2013) and zinc oxide (Azizi et al. 2014; Nagarajan and Arumugam Kuppusamy 2013; Pandimurugan and Thambidurai 2014). Collected intact cells of microalgae are exploited in the biosynthesis of gold- (Chakraborty et al. 2009; Lengke et al. 2006a; Parial et al. 2012a; Parial et al. 2012b; Senapati et al. 2012), silver- (Barwal et al. 2011; Jena et al. 2014; Lengke et al. 2007a; Li et al. 2015; Mahdieh et al. 2012; Patel et al. 2015), platinum- (Lengke et al. 2006b) and palladium- (Lengke et al. 2007b), copper oxide (Rahman et al. 2009) and iron-based (Subramaniyam et al. 2015) nano-objects. Purified algal proteins are exploited in the fabrication of nanoparticles made of gold (Xie et al. 2007a), silver (Xie et al. 2007b) and silver-gold bimetallic nanoparticles (Govindaraju et al. 2008). Furthermore, the pigment C-phycoerythrin, extracted from a marine cyanobacterium, is utilized for the production of CdS nanoparticles (MubarakAli et al. 2012).

The use of living cells of microalgae, more specifically cyanobacteria, maintained under their normal culturing conditions, for the biosynthesis of different nanomaterials was first reported by Brayner and colleagues (Brayner et al. 2007). This simple and 1-step process consists on, first, growing cells in a flask containing their culture media for a certain amount of time and, then, challenging the cells by aqueous solutions of metallic salts. As a result, the living cells act as green nanofactories inside which the production of the nanomaterials occurs. Although the mechanism underlying this phenomenon has yet to be fully investigated, a few papers provide with meaningful hints (Dahoumane et al. 2014b; Jeffryes et al. 2014; Rösken et al. 2014). The novelty of this methodology lies in the advantage taken from the enzymatic machinery of microalgae, whether they are unicellular or filamentous, to accomplish the 
production of the desired nanomaterials while the cells are maintained under their habitual culturing conditions offering hence the possibility for the design of bioreactors (Satapathy et al. 2014). Although in its early infancy, devising algae-based photobioreactors for the biosynthesis of various and valuable nanomaterials should witness tremendous developments in the near future owing to the ease of microalgae culturing and the various nanomaterials reported to date having been produced through this eco-friendly and expanding route (vide infra).

So far, several studies have described the biosynthesis of a myriad of nanomaterials using living cultures of microalgae belonging to five algal divisions. For instance, gold nanoparticles can be synthesized using living cultures of Charophyta Klebsormidium flaccidum and Cosmarium impressulum (Dahoumane et al. 2012a; Dahoumane et al. 2012b); Chlorophyta Kirchneriella lunaris (Dahoumane et al. 2014b), Pseudokirchneriella subcapitata (Halvorson Lahr and Vikesland 2014), Chlorella vulgaris (Luangpipat et al. 2011); Cyanophyta Anabaena sp. (Rösken et al. 2014), Synechocystis sp. (Focsan et al. 2011), Anabaena flos-aquae, Calothrix pulvinata and Leptolyngbya foveolarum - used also for the biosynthesis of Pt, Pd and Ag nanoparticles (Brayner et al. 2007); diatoms Eolimna minima (Feurtet-Mazel et al.), Diadesmis gallica and Navicula atomus (Schröfel et al. 2011); and Euglenozoa Euglena gracilis (Dahoumane et al. 2012a). In a similar manner, silver nanoparticles can be produced through the use of living cultures of Chlorella vulgaris (Mohseniazar et al. 2011) and Pseudochlorella kessleri (Kaduková et al. 2014); silvergold bimetallic alloy nanoparticles of well-controlled composition using living cultures of Chlorophyta Chlamydomonas reinhardtii (Dahoumane et al. 2014a); and iron oxide nanomaterials using Charophyta $K$. flaccidum (Brayner et al. 2009), Euglenozoa E. gracilis (Brayner et al. 2012), and Cyanophyta A. flosaquae (Dahoumane et al. 2010).

In this paper, we report on the improvement of the kinetics and the yield of biogenic gold nanoparticles using E. gracilis living cultures after the addition of tetrachloroauric acid aqueous solutions into the cultures by the mean of culture media switching from mineral medium - organic carbon-free, to lactate medium - a source of organic carbon. This change affects the rate of growth of E. gracilis and its viability, which, in turn, affect the features of gold biosynthesis, i.e., the kinetics, the yield and the characteristics of the so-fabricated gold nano-objects via E. gracilis-mediated route, i.e., the size, the shape and the colloidal stability.

\section{Materials and Methods}

\section{Euglena gracilis presentation and culturing conditions}

Euglena gracilis, E. gracilis (ALCP \#217), comes from the Muséum National d'Histoire Naturelle (Paris, France) Culture Collection. It is a unicellular motile protist belonging to the algal phylum of Euglenozoa, provided, in addition to a functional photosynthetic machinery, with the ability to perform phagocytosis. It can be cultured in a carbon-free, mineral (M) medium, i.e., under autotrophic conditions where cells perform only photosynthesis, or under mixotrophic conditions where cells are grown in organic carbon- 
rich media, such as lactate (L) medium, and exposed to light so the cells can rely on both photosynthesis and phagocytosis to grow. Both media, $\mathbf{M}$ and $\mathbf{L}$, derive from Bold Basal (BB) medium (Stein 1973). For the optimum growth of $E$. gracilis, the $\mathrm{pH}$ is brought to 3.6 by addition of $\mathrm{HCl} 1 \mathrm{~N}$, in the case of mineral (M) medium, and of a mixture of lactic acid / sodium lactate, in the case of lactate (L) medium. Finally, the media are autoclaved at $121^{\circ} \mathrm{C}$ for $20 \mathrm{~min}$ and stored at $4{ }^{\circ} \mathrm{C}$.

Starting from a stock culture of E. gracilis grown in L medium, the culture was transferred (10\% (v/v) of inoculum) into the culture medium. In duplicate, $10 \mathrm{~mL}$ of the stock culture were added into a sterile flask of $250 \mathrm{~mL}$ containing $90 \mathrm{~mL}$ of $\mathrm{L}$ medium and let to grow for 2 weeks before use in an incubator with a photoperiod of $16 \mathrm{~h}$ light / $8 \mathrm{~h}$ dark, at a controlled temperature of $20.0 \pm 1.0^{\circ} \mathrm{C}$ and luminosity (70-100 $\mu \mathrm{mol} \mathrm{m} \mathrm{m}^{-2} \mathrm{~s}^{-1} \mathrm{PPF}$ ) under ambient $\mathrm{CO}_{2}$ conditions. A similar procedure was followed for the launch of $E$. gracilis grown in $\mathbf{M}$ medium.

\section{Biosynthesis of Au-NPs using living cells of Euglena gracilis}

The biosynthesis of gold nanoparticles (Au-NPs) using living cells of $E$. gracilis cultured in $L(E g L)$ and $M$ (EgM) media was carried out as described previously (Dahoumane et al. 2012a). Typically, aqueous solutions of tetrachloroauric acid $\left(\mathrm{HAuCl}_{4}\right)$ were added into 2-week aged cultures. For $E g \mathrm{~L} 1$ and $E g \mathrm{M} \mathrm{1}$, a final $\mathrm{Au}(\mathrm{III})$ concentration of $10^{-3} \mathrm{M}$ was reached starting from an initial aqueous solution of $\mathrm{HAuCl}_{4}$ of $10^{-}$

${ }^{2} \mathrm{M}$; for $E g \mathrm{~L} 2$, a final $\mathrm{Au}(\mathrm{III})$ concentration of $10^{-4} \mathrm{M}$ was reached starting from an initial aqueous solution of $\mathrm{HAuCl}_{4}$ of $10^{-3} \mathrm{M}$. After $\mathrm{HAuCl}_{4}$ introduction, the flasks containing the cultures were put back into the incubator and gently hand-shaken twice a day.

\section{Characterization of Euglena gracilis cells and Au-NPs}

\section{Cell growth and viability}

The cell viability of $E g \mathrm{~L} 1, E g \mathrm{M} 1$ and $E g \mathrm{~L} 2$ was monitored by measuring the absorbance of chlorophyll a at different times before and after $\mathrm{HAuCl}_{4}$ addition. This photosynthetic pigment is extracted from $1 \mathrm{~mL}$ of $E$. gracilis cultures in $9 \mathrm{~mL}$ of acetone, according to an experimental protocol published by Ninfa et al. (Ninfa et al. 2010). After $1 \mathrm{~min}$ of vortex, the mixture is warmed up to $37{ }^{\circ} \mathrm{C}$ for $3 \mathrm{~min}$ and then centrifuged. The obtained supernatant is used to monitor, throughout the experiment, the evolution of chlorophyll a absorbance, centered at $663 \mathrm{~nm}$, by UV-Vis spectroscopy using a Cary 5E spectrophotometer.

\section{Au-NP absorbance}


The evolution of the surface plasmon resonance (SPR) band intensity over time of the as-produced gold colloids, after the addition of gold salt solutions into the three cultures of $E$. gracilis, was monitored by UV-Vis spectroscopy using a Cary 5E spectrophotometer. $\sim 2 \mathrm{~mL}$ of the colloids were scanned between 400 and $800 \mathrm{~nm}$, at different times.

\section{Optical microscopy}

Optical microscopy was performed with a Zeiss Primo Star microscope.

\section{TEM}

Transmission Electron Microscopy (TEM) micrographs of the released Au-NPs were obtained using a JEOL JEM $100 C X$ II UHR operating at $100 \mathrm{kV}$. Droplets of the supernatant taken from EgL1 containing Au-NPs were cast onto formvar-coated copper grids and water was allowed to evaporate.

\section{SEM-FEG}

Scanning electron microscopy using field emission gun (SEM-FEG) was performed using Zeiss Supra 40 operating at $20 \mathrm{kV}$. Secondary Electron Detector was used. Prior to observation, the samples were fixed using glutaraldehyde, dehydrated in acetone, and dried with a critical point dryer BAL-TEC CPD 030 with liquid $\mathrm{CO}_{2}$, critical point $31^{\circ} \mathrm{C}-73.8$ bar.

\section{Results and Discussion}

\section{Cell growth and viability}

To assess the rate of growth of $E$. gracilis when cultured in lactate (L) medium, Fig. 1 presents the absorbance of the photosynthetic pigments, i.e., chlorophylls a and c and carotenoids, extracted from 2week aged cultures. Each pigment has several components, indicated with black arrows in Fig. 1 a - D0 spectrum, overlapping with those of the other pigments. The absorbance of the chlorophyll a band, located at $\sim 663 \mathrm{~nm}$, is taken as an indicator of cell growth and viability. Before $\mathrm{HAuCl}_{4}$ introduction into the cultures, the intensity of this band gives $\sim 0.10$ and $\sim 0.08$ for flasks (a) and (b) (Fig. 1 a \& b - D0 spectrum, respectively). If the 10 -fold dilution factor is taken into account, this makes the chlorophyll a absorbance at $\sim 1.00$ and $\sim 0.80$ for the same flasks, respectively. These values have to be compared with the absorbance of chlorophyll a of the same species when cultured in mineral (M) medium. As depicted in Fig. 1 c - D0 spectrum, the 2-week aged flask of E. gracilis, grown in M medium, displays an 
absorbance of $\sim 0.012$ for the chlorophyll a, $\sim 0.12$ if the dilution factor is taken into account (Dahoumane et al. 2012a; Dahoumane et al. 2014b). This means that E. gracilis has a rate of growth 7-8 times faster when grown in $\mathrm{L}$ medium compared to $\mathrm{M}$ medium. In other words, $\mathrm{L}$ medium contributes to the greater part of the growth vs. photosynthesis. This fast rate of growth has a direct consequence on the ability of the cultures to handle the introduced tetrachloroauric cations (vide infra).

The addition of tetrachloroauric acid aqueous solutions into the cultures triggered two distinct behaviors of E. gracilis cultures. At $10^{-3} \mathrm{M}$, the chlorophyll a signal totally disappeared 8 days after (Fig. 1 a \& C - D8 spectrum). Two weeks later (Fig. 1 a \& c - D14 spectrum), no sign of recovery was recorded. Unlike the two previous cases, chlorophyll a maintained its amount within the culture 8 days after $\mathrm{Au}$ (III) addition at $10^{-4} \mathrm{M}$ (Fig. 1 b - D0 and D8 spectra) and witnessed a slight increase 6 days later (Fig. 1 b - D14 spectrum). In other words, the culture underwent a partial damage during the first week caused by the toxicity of $\mathrm{Au}(\mathrm{III})$ cations but soon recovered by reaching its initial growth level and then continued multiplying. These findings confirm our previously reported results, i.e., in all cases, $10^{-3} \mathrm{M}$ of $\mathrm{Au}(\mathrm{III})$ is a lethal dose for microalgae cells while $10^{-4} \mathrm{M}$ of $\mathrm{Au}(\mathrm{III}) \mathrm{can}$, in some cases, inhibit the cell growth for a short while but without any significant incidence on the cell growth at a long course (Dahoumane et al. 2012a; Dahoumane et al. 2014b).

Notably, the use of acetone as chlorophyll a extracting agent led to the disappearance of the SPR band due to the absorbance of Au-NPs in all spectra. So far, this band remained visible when chlorophyll a absorbance was measured in the case of only $K$. lunaris and $C$. reinhardtii used as nanofactories for the biosynthesis of Au-NPs (Dahoumane et al. 2014b), and Au-, Ag- and Ag/Au bimetallic alloy NPs (Dahoumane et al. 2014a), respectively. The persistence of the SPR band in the case of these two green microalgae species is due to the protection of the as-synthesized metallic NPs ensured by the adsorption of the cell-produced mucilages onto the NP surface through a strong interaction. As E. gracilis is not known to produce any exopolysaccharides, the so-fabricated nanoparticles might not offer any stability. However, when grown in L medium, the lactate may act as the capping agent offering therefore a relatively average stability that could not withstand the action of acetone. 


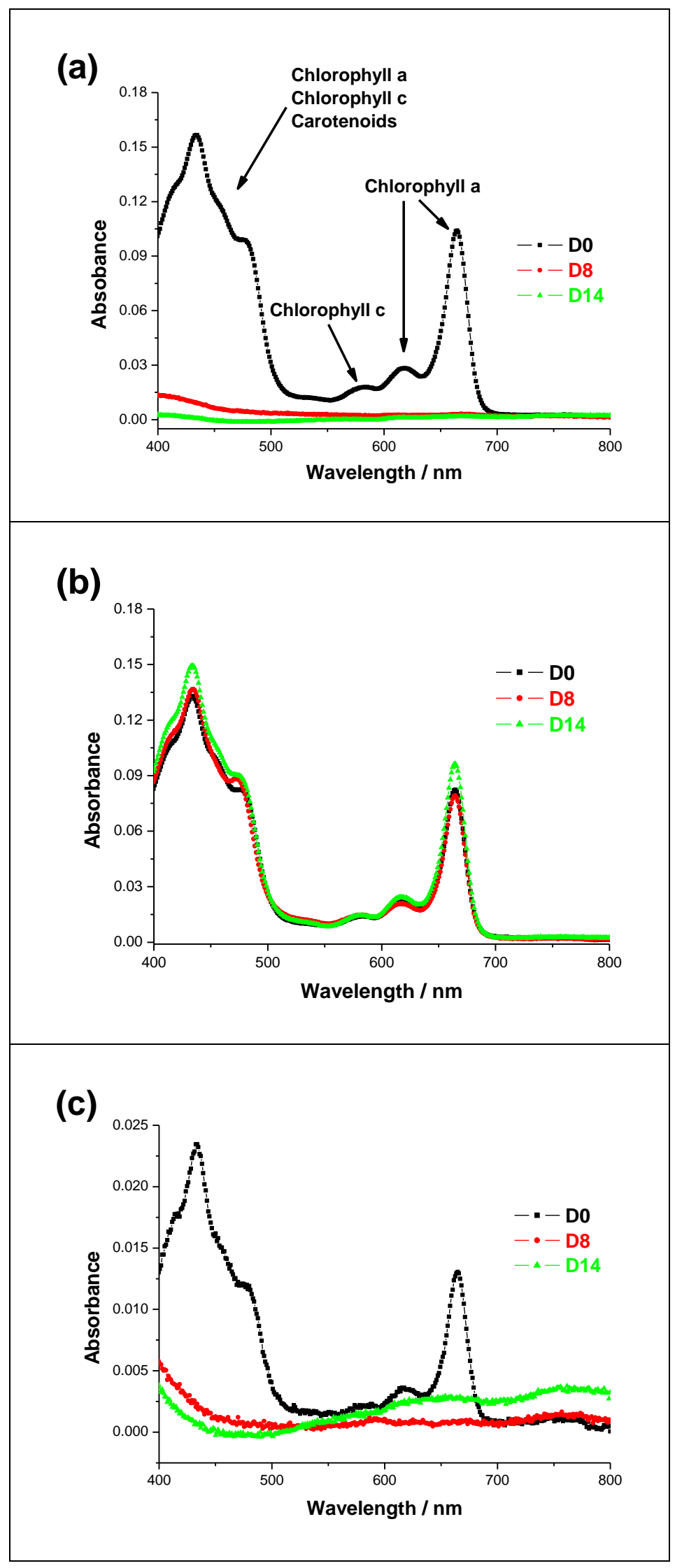


Figure 1. Evolution of the absorbance of acetone-extracted photosynthetic pigments of 2-week old $E$. gracilis grown in $\mathrm{L}(E g \mathrm{~L})(\mathrm{a} \& \mathrm{~b})$ and in $\mathrm{M}(E g \mathrm{M})(\mathrm{c})$ culture media before (D0 spectrum) and after the addition of aqueous $\mathrm{HAuCl}_{4}$ solution: 8 and 14 days (D8 and D14 spectra, respectively) later at $10^{-3} \mathrm{M}$ (a and $\mathrm{c}$ ) and $10^{-4} \mathrm{M}(\mathrm{b})$. The black arrows in (a - D0 spectrum) indicate the components of these pigments, i.e., chlorophylls a and $\mathrm{c}$ and carotenoids.

\section{Macroscopic aspect of Euglena gracilis cultures}

The macroscopic aspect of E. gracilis cultures grown in L medium is in good agreement with the recorded spectra of the chlorophyll a, i.e., the more intense is the absorbance of chlorophyll a, the darker green is the colour of the flasks containing the cultures. In fact, as depicted in Fig. 2 a-1 and b-1, the 2-week aged cultures of $E$. gracilis grown in L medium ( $\mathrm{a}-1$ and $\mathrm{b}-1$ photographs) appear completely dark green compared to when grown in $\mathrm{M}$ medium which presents a lighter green colour (c-1 photograph). This is due to the fact that $E$. gracilis in L medium feeds predominantly directly from its nourishing medium in addition to carrying out photosynthesis.

One day after the addition of the chloroauric cations into the flasks at $10^{-3} \mathrm{M}$, the colour shifts from dark green into dark purple in the case of EgL 1 (Fig. 2 - a-2 photograph) and from light green into brown in the case of EgM 1 (Fig. 2 - c-2 photograph), respectively. This colour change evidences the transformation of cationic gold into its zero-valent counterpart. However, no change is noticed in the case of $E g L 2\left(\left[\mathrm{Au}^{3+}\right]=10^{-4} \mathrm{M}\right)$ where the culture remains dark green (Fig. $2-$ b-2 photograph).

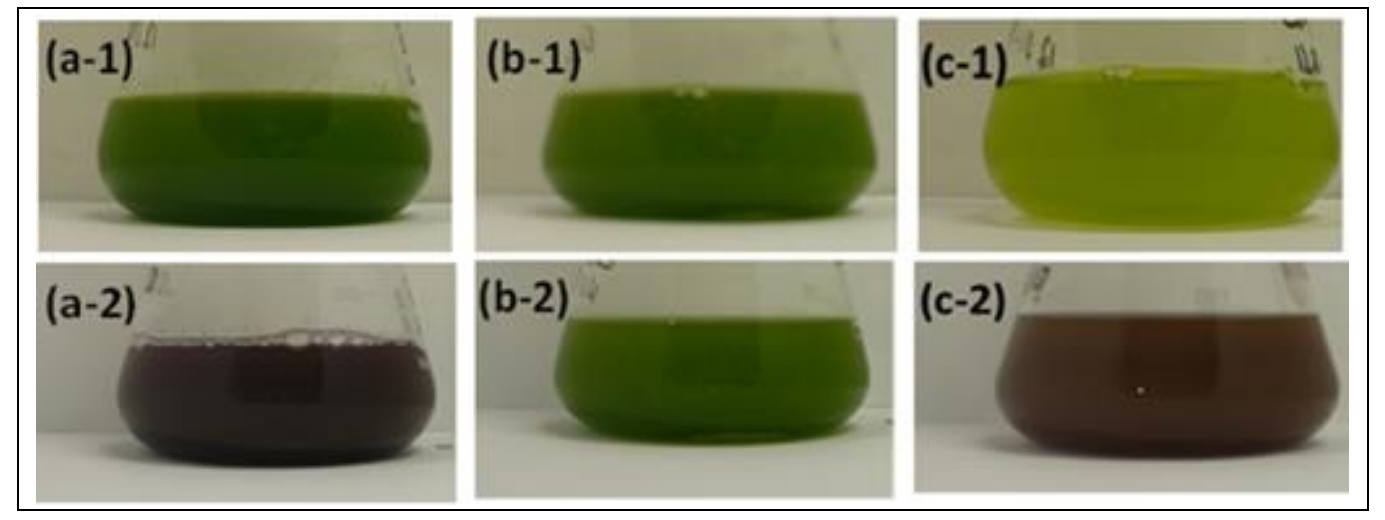

Figure 2. Evolution of the macroscopic aspect of E. gracilis cultures grown in L (a \& b) and $\mathrm{M}$ media (c) before (a-1, b-1 and c-1) and one day ( $D+1)$ after the addition of tetrachloroauric acid aqueous solution $\left(\mathrm{HAuCl}_{4}\right)$ at $10^{-3} \mathrm{M}(\mathrm{a}-2$ \& $\mathrm{c}-2)$ and $10^{-4} \mathrm{M}(\mathrm{b}-2)$. 


\section{Photonic imaging of Euglena gracilis cells}

To check whether the production of Au-NPs by E. gracilis cultured in L medium is an intracellular process, similarly to when cultured in M medium (Dahoumane et al. 2012a), and having in mind that lactic acid was reported to promote the synthesis of gold nanoparticles by acting as the reducing agent under boiling conditions (Yin et al. 2010), we decided to pick up a small volume of $E g$ L 1culture medium after gold cations were added at a concentration of $10^{-3} \mathrm{M}$ and imaged the sample using an optical microscope. As shown in Fig. 3, all compartments of E. gracilis cells became purple proving therefore that the cells internalized the introduced $\mathrm{Au}(\mathrm{III})$ and reduced them through an intracellular process into metallic gold $(\mathrm{Au}(0))$ before releasing the as-generated $\mathrm{Au}$-NPs into culture media demonstrating thus that, for E. gracilis, the same 3-step intracellular process regarding Au-NP biosynthesis occurs in both culture media: (i) uptake of $A u(I I I)$; (ii) reduction of $A u(I I I)$ into $A u(0)$ and subsequent $A u-N P$ generation; and (iii) release of the as-produced Au-NPs into culture media. Moreover, the image highlights the wellknown characteristic of $E$. gracilis regarding its ability to change steadily its shape and size. In fact, the three shown cells display different shapes and sizes; two of them are accolated while the third one is shown enveloped in a kind of a purple cloud. This last fact may be explained by two reasons: the cell lysis leading to the release of the intracellular components overloaded with intracellular Au-NPs due to the toxicity of these objects and/or the cell is erupting due to the applied pressure by the two glass slides used for imaging.

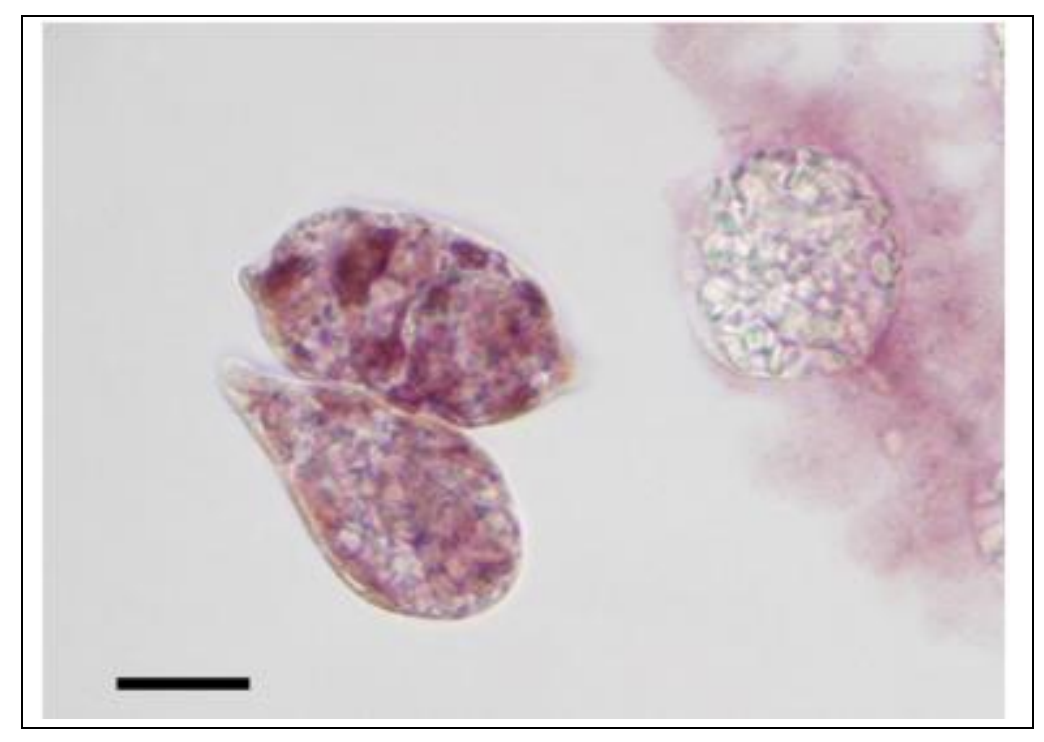

Figure 3. Optical image of $E$. gracilis cells grown in $\mathrm{L}$ medium and challenged with $10^{-3} \mathrm{M}$ of $\mathrm{HAuCl}_{4}$ aqueous solution ( $E g \mathrm{~L} 1$ sample). Scale bar: $10 \mu \mathrm{m}$. 


\section{State of the surface of Euglena gracilis}

The surface of $E$. gracilis cells, taken from $E g \mathrm{~L} 1$ sample - cultured in $\mathrm{L}$ medium and challenged by $10^{-3} \mathrm{M}$ of $\mathrm{Au}(\mathrm{III})$, was characterized using scanning electron microscopy using a field emission gun (SEM-FEG). Fig. 4 a displays a whole cell of $E$. gracilis with a preserved outer structure. At the top of the micrograph, the longest flagellum, indicated with the red arrow, can be distinguished easily at the cell apex. Moreover, the pellicle, made of strips spiraling around the cell, is also neatly visible. This pellicle ensures to $E$. gracilis its flexibility, i.e., perpetual changes in shape and size, and its contractility making it motile. At this magnification, it is hard to distinguish any Au-NPs located at the surface of the cells. Beside depicting the well preserved pellicle and the absence of any damage, higher magnification (Fig. 4 b) on a part of the previous image shows spots with 3 level of brightness due to the presence of Au-NPs at 3 different compartments: (i) the brightest spots are located on the cell surface; (ii) the palest ones are located within the cell in the shallow compartments; and (iii), with an in-between brightness, the nanoobjects located under the cell surface and about to be released from the cells. These findings corroborate the intracellular formation of these nanoparticles which diffuse to the cell-wall where they are released into culture media (Dahoumane et al. 2012a). A deeper look on the nanoparticles located on the surface of $E$. gracilis allows to notice that these Au-NPs seem to form a homogenous population sharing the same characteristics with a spherical shape and a narrow distribution in size. The presence of particular shapes, such as triangles and hexagons, indicated in red arrows in Fig. 4, is very scarce. 

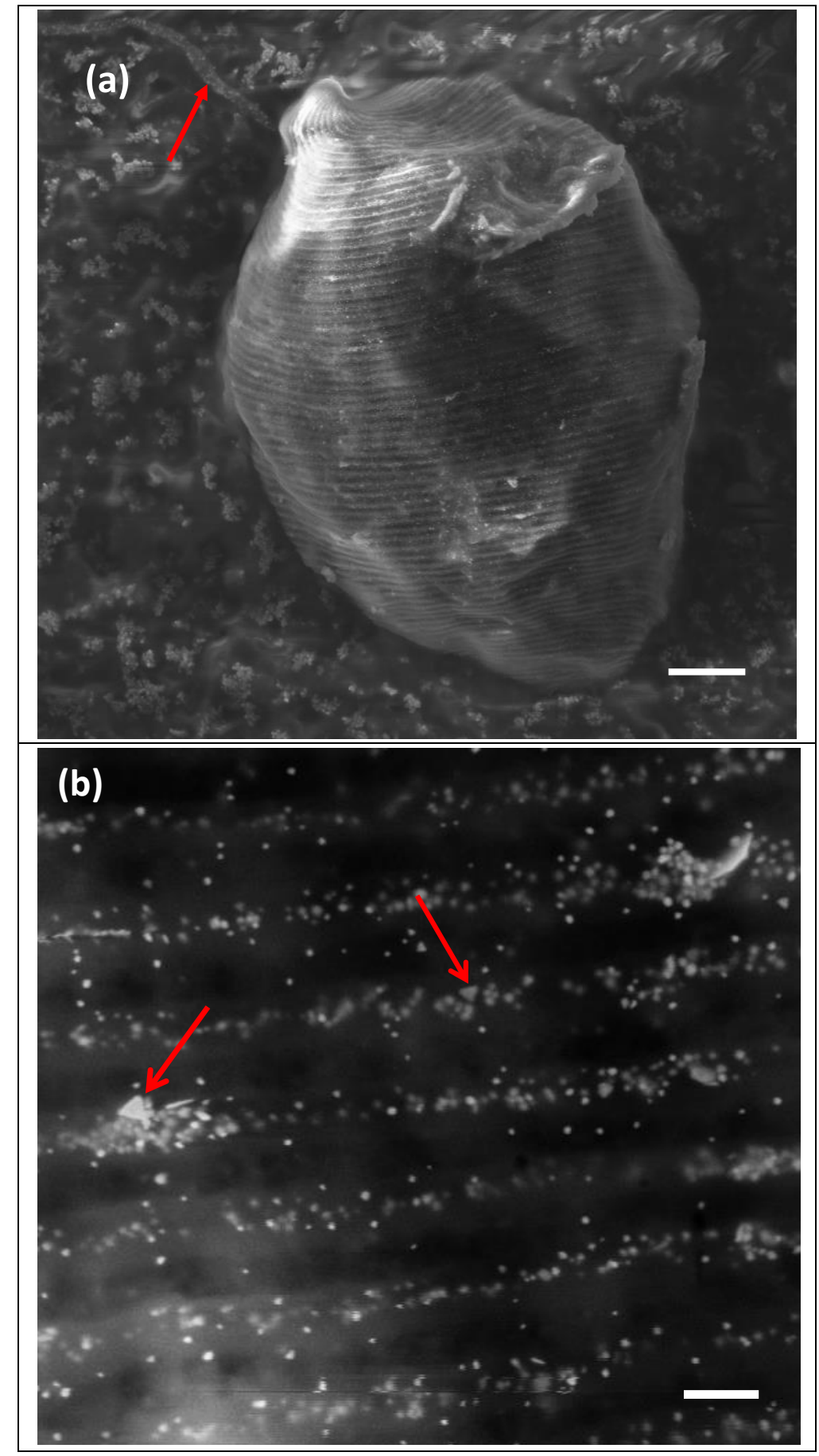

Figure 4. SEM-FEG micrographs of: (a) a whole cell of $E$. gracilis grown in L medium and challenged with $\mathrm{Au}(\mathrm{III})$ at $10^{-3} \mathrm{M}(\mathrm{Eg} \mathrm{L} 1)$. The red arrow indicates the cell longest flagellum; and (b) a higher magnification of a part of the same cell. Red arrows indicate visible gold nanoparticles under the shape of a triangle on the surface of E. gracilis. Scale bar: $2 \mu \mathrm{m}$ (a) and $200 \mathrm{~nm}$ (b). 


\section{Shape and size of biogenic gold nanoparticles}

Two weeks after the living cells of $E$. gracilis were challenged by tetrachloroauric acid at a concentration of $10^{-3} \mathrm{M}(E g \mathrm{~L} 1)$, a small volume of the supernatant was examined under an electron transmission microscope (TEM) in order to study the shape and the size of the released Au-NPs from the cells into the culture medium (Fig. 5). Overall, the nanoparticles look well-defined and well-dispersed and do not aggregate. Mainly, three major populations of Au-NPS can be easily distinguished: small round-shaped nanoparticles of less than $10 \mathrm{~nm}$ in diameter, big round-shaped nanoparticles of tens of $\mathrm{nm}$ in diameter, and nanoparticles under the shape of triangle, truncated triangles, pentagons and hexagons, referred to with red arrows in Fig. 5 a \& b, whose dimensions vary from a few nanometers to tens of nanometers. In the absence of SEM micrographs, these TEM images cannot allow to state whether these particular shapes exhibit the same depth and could be coined as nanoplates or not. The first two sorts of Au-NPs are also visible when E. gracilis is grown in mineral medium (Dahoumane et al. 2012a; Dahoumane et al. 2014b). However, the latter occurs only in the present case, i.e., in L medium and are not seen when $E$. gracilis is grown in mineral $(\mathrm{M})$ medium $(\mathrm{EgM})$ and challenged with gold cations at $10^{-3} \mathrm{M}$ and $10^{-4} \mathrm{M}$ (Dahoumane et al. 2012a; Dahoumane et al. 2014b). Therefore, Au-NPs, under the shape of triangles, pentagons and hexagons, could not be formed through an intracellular process. Indeed, the ultrastructure of several species of microalgae, including $E$. gracilis grown in $\mathrm{M}$ medium, involved in the bioproduction of Au-NPs does not show such shapes within the cells (Brayner et al. 2007; Dahoumane et al. 2012b). This fact is supported by the recent study by Li et al. who carried out the synthesis of Ag-NPs using two different strains of Euglena (Li et al. 2015). Moreover, a meticulous examination of the surface of E. gracilis, from our experiment, i.e., EgL 1, using SEM-FEG, demonstrates that Au-NPs under these shapes are not visible within the cells just beneath the cell surface and are very scarce on the surface of the cells (cf. Fig. 4). We think the apparition of Au-NPs under these shapes, i.e., truncated triangles, pentagons and hexagons, may likely be due to the combination of two factors: the mass cell lysis, caused

by the toxicity of $\mathrm{Au}(\mathrm{III})$ at $10^{-3} \mathrm{M}$, triggers the release of biomolecules from the cells; once in culture medium, these biomolecules can act along with lactate as reducing agents yielding to extracellular biosynthesis of Au-NPs or alteration of the features, i.e., the shape and the size, of Au-NPs synthesized via an intracellular process; finally, the lactate and the available released biomolecules from lysed cells, by adsorbing preferentially on certain facets of the growing nuclei and modifying their relative growth rates, may direct the shape of the Au-NPs leading therefore to the formation of these particular Au-NPs. The ability of lactate to reduce gold cations and to direct the shape of the as-produced NPs was discussed in the paper by Yin et al. (Yin et al. 2010). 


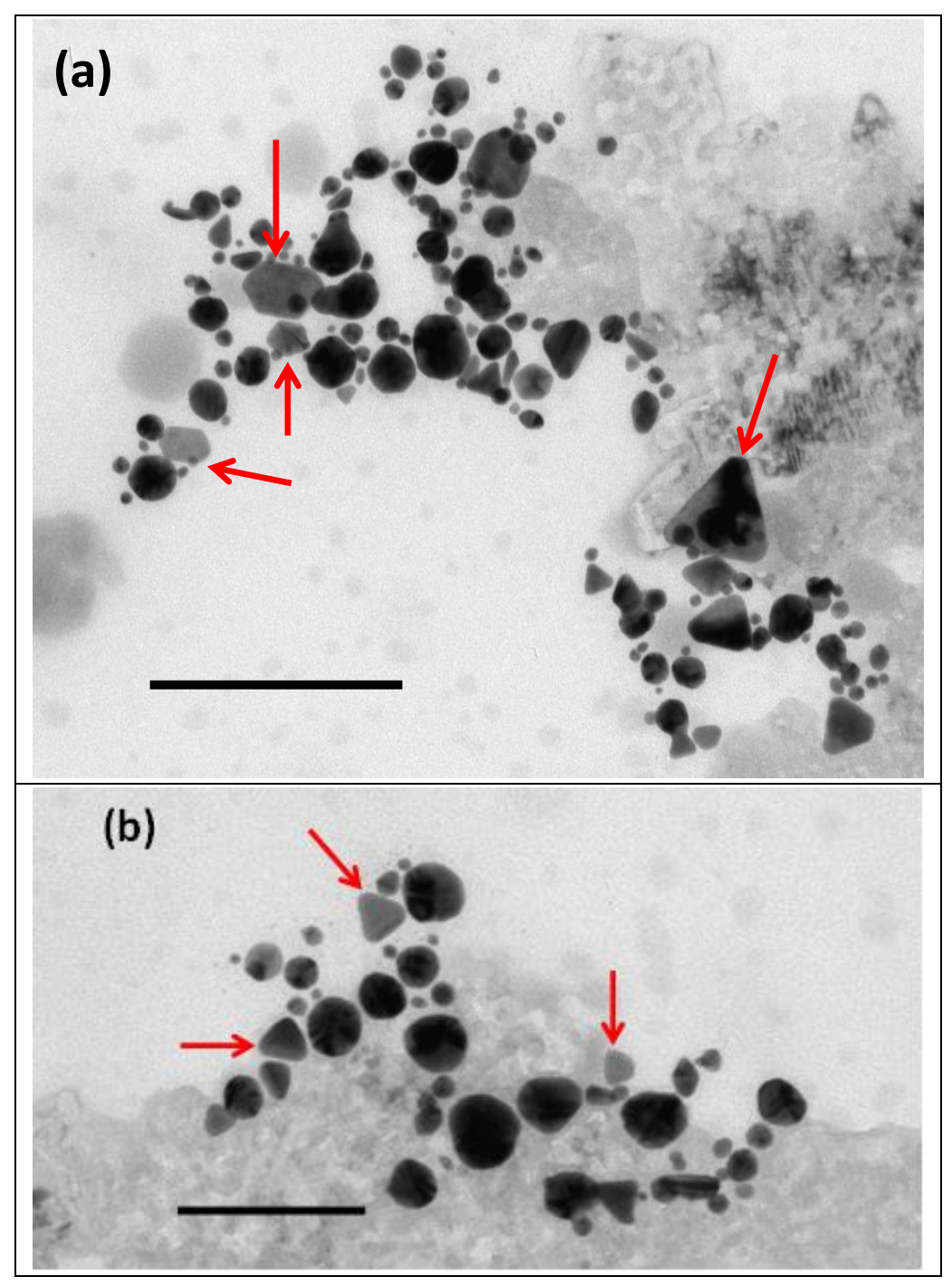

Figure 5. TEM micrographs of released Au-NPs taken from E. gracilis supernatant grown in L medium $\left(E g L 1,\left[\mathrm{Au}^{3+}\right]=10^{-3} \mathrm{M}\right)$. Arrows in red indicate some Au-NPs of particular shape, such as triangle, pentagon and hexagon. Scale bar: $200 \mathrm{~nm}(\mathrm{a})$ and $100 \mathrm{~nm}$ (b).

\section{Kinetics, yield and colloidal stability}

In order to compare the features of the as-produced gold nanoparticles, i.e., the kinetics, the yield and the colloidal stability, between $\operatorname{Eg} \mathrm{L} 1\left(\left[\mathrm{Au}^{3+}\right]=10^{-3} \mathrm{M}\right), \operatorname{EgL} 2\left(\left[\mathrm{Au}^{3+}\right]=10^{-4} \mathrm{M}\right)$ and $\operatorname{EgM} 1\left(\left[\mathrm{Au}^{3+}\right]=10^{-3} \mathrm{M}\right)$, the intensity of the SPR band, due to the presence of nano-gold within each sample, was recorded using UV-Vis spectroscopy at different times and the results are summed up in Fig. 6. One day after Au(III) addition, EgL 1 sample displays a unique and intense SPR band (Fig. 6 a-1 - D1 spectrum). The intensity of this SPR band seems to have reached its maximum at this time as the spectra D3, D6 and D9, recorded respectively 3, 6 and 9 days after $\mathrm{Au}(\mathrm{III})$ introduction, look almost identical with D1 (Fig. 6 a-1 - D3, D6 
and D9 spectra). This is confirmed by the plateau obtained when the maximum of the absorbance vs. time is plotted (Fig. 6 a-2).

At first, the UV-Vis spectra of $E g L 2\left(\left[\mathrm{Au}^{3+}\right]=10^{-4} \mathrm{M}\right)$ do not present any SPR band a day after the introduction of $\mathrm{Au}(\mathrm{III})$ into $\mathrm{Eg} \mathrm{L} 2$ culture (Fig. $6 \mathrm{~b}$ - D1 spectrum). Then, an SPR band, of a minor intensity, appears two days later (Fig. 6 b - D3 spectrum). This band seems to vanish almost totally over time (D6 and D9 spectra of the same figure). This confirms why it was not possible to image the Au-NPs produced by this sample using TEM as the few produced nano-structured objects were likely either retained within the cells or surrounded by a vigorous and still-growing population of cells. This fact is in good agreement with the macroscopic aspect of this sample and with the evolution of the intensity of the chlorophyll a, pointing out that this amount of gold is not lethal. The viability and the growth of the cells explain the presence of other absorption bands in the same spectra (Fig. 6 b) due most likely to the different photosynthetic pigments.

In the case of $E g M 1\left(\left[\mathrm{Au}^{3+}\right]=10^{-3} \mathrm{M}\right)$, the intensity of the SPR band reaches its maximum a day after $\mathrm{Au}$ (III) addition (Fig. $6 \mathrm{c}$ - D1 spectrum) and then diminishes over time while slightly broadening evidencing the aggregation and the sedimentation of the bioproduced Au-NPs (D3, D6 and D9 spectra of the same figure). As in the previous case, 2 other bands are persistent and are also most likely due to the photosynthetic pigments.

At this point, several remarks could easily be drawn. (i) The unique and well defined band observed in UV-Vis spectra (Fig. 6 a-1) means that Au-NPs are in their vast majority spherical. (ii) The SPR band plateauing one day after $\mathrm{Au}(\mathrm{III})$ introduction into $\mathrm{EgL} 1\left(\left[\mathrm{Au}^{3+}\right]=10^{-3} \mathrm{M}\right)$ indicates that the rate of Au-NPs production using $E$. gracilis, grown in L medium, is quite fast (Fig. 6 a-2) and faster than in the case of $K$. flaccidum, for instance, reported in a previous work (Dahoumane et al. 2012a), which displays a slower kinetics by accomplishing this task within several days after being challenged by the same amount of gold cations $\left(\left[\mathrm{Au}^{3+}\right]=10^{-3} \mathrm{M}\right)$. (iii) Gathered data for the two species brings out the yield of Au-NP biosynthesis is higher in the case of $E g \mathrm{~L} 1$ compared to $K$. flaccidum (Dahoumane et al. 2012a). In fact, the SPR band intensity reaches $\sim 0.75$ in absorbance in the case of $E g \mathrm{~L} 1$ vs. $\sim 0.6$ in the case of $K$. flaccidum challenged with the same amount of $\mathrm{Au}(\mathrm{III})\left(10^{-3} \mathrm{M}\right)$. (iv) The produced Au-NPs using grown cells of $E$. gracilis in $\mathrm{L}$ medium $\left(\mathrm{EgL} 1,\left[\mathrm{Au}^{3+}\right]=10^{-3} \mathrm{M}\right.$ ) exhibit a better colloidal stability compared to AuNPs made by $E$. gracilis cells grown in $\mathrm{M}$ medium whether at $10^{-3} \mathrm{M}$ (EgM 1, Fig. 6 b) or $10^{-4} \mathrm{M}$ of $\mathrm{Au}$ (III) (Dahoumane et al. 2014b). The fast kinetics and the high yield of Au-NP biosynthesis are due most likely to the fast rate of growth of E. gracilis cells when cultured in L medium making higher amounts of enzymatic machinery available to carry out the work; the better colloidal stability of the as-produced nano-structures is likely ensured by the remaining molecules of lactate by adsorbing onto their surface. As a reminder, E. gracilis is not known to produce any exopolysaccharides (EPS). Moreover, the nature of the interaction between the lactate molecules and the Au-NPs has yet to be clarified. Au-NPs were only stabilized in the presence of lactate, therefore the presence of cell lysis components can be excluded as the stabilizing agent. In fact, Au-NPs made using grown cells of E. gracilis in mineral medium (EgM) lack colloidal stability even if the added gold cations, whether at a concentration of $10^{-4} \mathrm{M}$ (Dahoumane et al. $2014 \mathrm{~b}$ ) or $10^{-3} \mathrm{M}$ (Figs. $1 \mathrm{c}$ and $6 \mathrm{c}$ ), trigger each time a mass cell death. 
The slight red-shift in the SPR band of $\sim 5 \mathrm{~nm}$, indicated with a black arrow in Fig. 6 a-1, may be linked mainly to the evolution in the composition of the surrounding medium of Au-NPs due to the release of large amounts of biomolecules, organic matter and cell debris, triggered by the mass cell death following the introduction of $\mathrm{Au}(\mathrm{III})$ into the culture at a lethal dose $\left(10^{-3} \mathrm{M}\right)$. This fact was observed previously with other species even if it was not commented (Dahoumane et al. 2012a). Indeed, a deeper look to the kinetics of gold nanoparticle release by, for instance, $K$. flaccidum following the addition of tetrachloroauric acid at $10^{-3} \mathrm{M}$ or by $A$. flos-aquae following the addition of tetrachloroauric acid at $10^{-4}$ M (cf. Fig. 2-a \& e of Ref. (Dahoumane et al. 2012a), respectively), reveals clearly the existence of the same phenomenon which could be easily correlated to the mass death of these two species as evidenced by the disappearance of the chlorophyll a fluorescence measured using PAM (Pulse Amplitude Modulated) fluorimeter (cf. Fig. 9-a \& d of Ref. (Dahoumane et al. 2012a), respectively). In addition to that, other factors may contribute to that minor red-shift, such a stronger interaction between the AuNPs due to improved yield and bigger Au-NPs being produced starting from smaller ones synthesized inside the cells and released into culture medium where they might have undergone an increase in size by the reduction of gold cations at their surface.

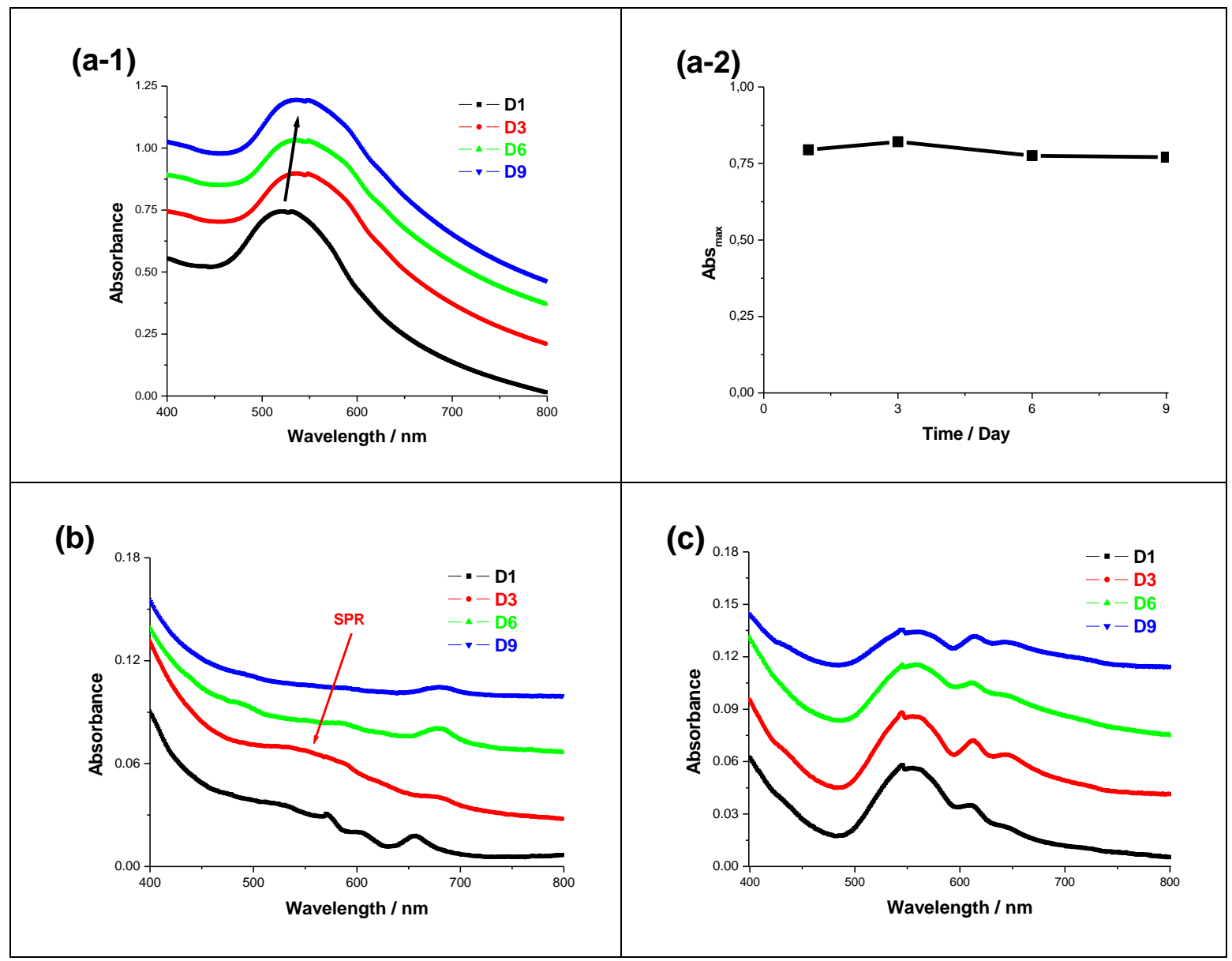


Figure 6. Evolution of the absorbance of bioproduced Au-NPs over time by: $(\mathrm{a}-1) E g \mathrm{~L} 1\left(\left[\mathrm{Au}^{3+}\right]=10^{-3} \mathrm{M}\right)$, (b) $E g L 2\left(\left[\mathrm{Au}^{3+}\right]=10^{-4} \mathrm{M}\right)$, and (c) $E g \mathrm{M} 1\left(\left[\mathrm{Au}^{3+}\right]=10^{-3} \mathrm{M}\right)$. (a-2) Release kinetics of produced Au-NPS by $E g \mathrm{~L}$ 1. Black arrow in (a-1) indicates a redshift of the SPR band for Au-NPs picked from $E g \mathrm{~L} 1$. Red arrow in (b) points out the vanishing SPR band of Au-NPs taken from EgL 2.

\section{Conclusion}

This study demonstrates that the metabolism of living cells of E. gracilis microalga has an important impact on its ability to modulate the biosynthesis of gold nanoparticles. In fact, mixotrophic conditions, i.e, photosynthesis and a source of organic carbon, i.e., E. gracilis grown in L medium and allowed to perform photosynthesis as it is exposed to a photoperiod of $16 \mathrm{~h} / 8 \mathrm{~h}$ light/dark, induce a cell growth several times faster than when the cells are grown under autotrophic conditions, i.e., photosynthesis. As a result, the kinetics of Au-NP biosynthesis become quicker and the yield higher due to the presence of larger amounts of living cells acting as nanofactories internalizing $\mathrm{Au}(\mathrm{III})$ cations and reducing them to zero-valent gold $(\mathrm{Au}(0))$, promoting therefore Au-NP production. Moreover, the colloidal stability of the as-produced nano-objects is significantly improved most likely due to the adsorption of remaining molecules of lactate onto the nanoparticles. These molecules are also probably responsible for the apparition of particular shapes among the population of Au-NPs. These findings add up to the amassed knowledge on the biosynthesis of nanoparticles using biological resources, in general, and living cells of microalgae, in particular, tackling key-factors that govern such processes therefore paving the way to the design of photobioreactors for the scalable and eco-friendly production of valuable nanomaterials.

\section{Conflict of interest}

The authors report no conflict of interest.

\section{Acknowledgements}

SAD thanks the French Ministry of Higher Education and Scientific Research for financial support. 


\section{References}

Azizi S, Ahmad MB, Namvar F, Mohamad R (2014) Green biosynthesis and characterization of zinc oxide nanoparticles using brown marine macroalga Sargassum muticum aqueous extract. Mater Lett 116:275-277. doi:10.1016/j.matlet.2013.11.038

Barwal I, Ranjan P, Kateriya S, Yadav SC (2011) Cellular oxido-reductive proteins of Chlamydomonas reinhardtii control the biosynthesis of silver nanoparticles. J Nanobiotechnol 9:56. doi:10.1186/1477-3155-9-56

Brayner R et al. (2007) Cyanobacteria as bioreactors for the synthesis of $\mathrm{Au}, \mathrm{Ag}, \mathrm{Pd}$, and Pt nanoparticles via an enzyme-mediated route. J Nanosci Nanotechno 7:2696-2708. doi:10.1166/jnn.2007.600

Brayner R et al. (2012) Intracellular biosynthesis of superparamagnetic 2-lines ferri-hydrite nanoparticles using Euglena gracilis microalgae. Colloid Surface B 93:20-23. doi:10.1016/j.colsurfb.2011.10.014

Brayner R et al. (2009) Photosynthetic microorganism-mediated synthesis of akaganeite (beta-FeOOH) nanorods. Langmuir 25:10062-10067. doi:10.1021/la9010345

Castro L, Blazquez ML, Munoz JA, Gonzalez F, Ballester A (2013) Biological synthesis of metallic nanoparticles using algae. IET Nanobiotechnol 7:109-116. doi:10.1049/iet-nbt.2012.0041

Castro L, Blázquez ML, Muñoz JA, González F, Ballester A (2014) Mechanism and applications of metal nanoparticles prepared by bio-mediated process. Rev Adv Sci Eng 3:199-216. doi:10.1166/rase.2014.1064

Chakraborty N, Banerjee A, Lahiri S, Panda A, Ghosh AN, Pal R (2009) Biorecovery of gold using cyanobacteria and an eukaryotic alga with special reference to nanogold formation - A novel phenomenon. J Appl Phycol 21:145-152. doi:10.1007/s10811-008-9343-3

Dahoumane SA, Djédiat C, Yeprémian C, Couté A, Fiévet F, Brayner R (2010) Design of magnetic akaganeite-cyanobacteria hybrid biofilms. Thin Solid Films 518:5432-5436. doi:10.1016/j.tsf.2010.04.001

Dahoumane SA, Djediat C, Yéprémian C, Couté A, Fiévet F, Coradin T, Brayner R (2012a) Species selection for the design of gold nanobioreactor by photosynthetic organisms. J Nanopart Res 14:883. doi:10.1007/s11051-012-0883-8

Dahoumane SA, Djédiat C, Yeprémian C, Couté A, Fiévet F, Coradin T, Brayner R (2012b) Recycling and adaptation of Klebsormidium flaccidum microalgae for the sustained production of gold nanoparticles. Biotechnol Bioeng 109:284-288. doi:10.1002/bit.23276

Dahoumane SA, Wijesekera K, Filipe CD, Brennan JD (2014a) Stoichiometrically controlled production of bimetallic gold-silver alloy colloids using micro-alga cultures. J Colloid Interface Sci 416:67-72. doi:10.1016/j.jcis.2013.10.048

Dahoumane SA, Yéprémian C, Djédiat C, Couté A, Fiévet F, Coradin T, Brayner R (2014b) A Global approach of the mechanism involved in the biosynthesis of gold colloids using micro-algae. $J$ Nanopart Res 16:2607. doi:10.1007/s11051-014-2607-8

Feurtet-Mazel A, Mornet S, Charron L, Mesmer-Dudons N, Maury-Brachet R, Baudrimont M Biosynthesis of gold nanoparticles by the living freshwater diatom Eolimna minima, a species developed in river biofilms. Environ Sci Pollut Res doi:10.1007/s11356-015-4139-x

Focsan M, Ardelean II, Craciun C, Astilean S (2011) Interplay between gold nanoparticle biosynthesis and metabolic activity of cyanobacterium Synechocystis sp. PCC 6803. Nanotechnology 22(485101). doi:10.1088/0957-4484/22/48/485101

Govindaraju K, Basha SK, Kumar VG, Singaravelu G (2008) Silver, gold and bimetallic nanoparticles production using single-cell protein (Spirulina platensis) Geitler. J Mater Sci 43:5115-5122. doi:10.1007/s10853-008-2745-4 
Govindaraju K, Kiruthiga V, Kumar VG, Singaravelu G (2009) Extracellular synthesis of silver nanoparticles by a marine alga, Sargassum Wightii Grevilli and their antibacterial effects. J Nanosci Nanotechno 9:5497-5501. doi:10.1166/jnn.2009.1199

Halvorson Lahr R, Vikesland PJ (2014) Surface-enhanced Raman spectroscopy (SERS) cellular imaging of intracellulary biosynthesized gold nanoparticles. ACS Sustainable Chem Eng 2:1599-1608. doi:10.1021/sc500105n

Jeffryes C, Agathos SN, Rorrer G (2014) Biogenic nanomaterials from photosynthetic microorganisms. Curr Opin Biotechnol 33:23-31. doi:10.1016/j.copbio.2014.10.005

Jena J, Pradhan N, Nayak RR, Dash BP, Sukla LB, Panda PK, Mishra BK (2014) Microalga Scenedesmus sp.: A potential low-cost green machine for silver nanoparticle synthesis. J Microbiol Biotechn 24:522-533. doi:10.4014/jmb.1306.06014

Kaduková J, Velgosová O, Mražíková A, Marcinčáková R (2014) The effect of culture age and initial silver concentration on biosynthesis of Ag nanoparticles. Nova Biotechnol Chim 13:28-37. doi:10.2478/nbec-2014-0004

Kannan RRR, Arumugam R, Ramya D, Manivannan K, Anantharaman P (2013a) Green synthesis of silver nanoparticles using marine macroalga Chaetomorpha linum. Appl Nanosci 3:229-233. doi:10.1007/s13204-012-0125-5

Kannan RRR, Stirk WA, Van Staden J (2013b) Synthesis of silver nanoparticles using the seaweed Codium capitatum P.C. Silva (Chlorophyceae). S Afr J Bot 86:1-4. doi:10.1016/j.sajb.2013.01.003

Klaus-Joerger T, Joerger R, Olsson E, Granqvist C-G (2001) Bacteria as workers in the living factory: Metalaccumulating bacteria and their potential for materials science. Trend Biotechnol 19:15-20. doi:10.1016/S0167-7799(00)01514-6

Kumar P, Govindaraju M, Senthamilselvi S, Premkumar K (2013) Photocatalytic degradation of methyl orange dye using silver (Ag) nanoparticles synthesized from Ulva lactuca. Colloid Surface B 103:658-661. doi:10.1016/j.colsurfb.2012.11.022

Kumar P, Senthamil Selvi S, Govindaraju M (2012a) Seaweed-mediated biosynthesis of silver nanoparticles using Gracilaria corticata for its Antifungal activity against Candida spp. Appl Nanosc 3:495-500. doi:10.1007/s13204-012-0151-3

Kumar P, Senthamil Selvi S, Lakshmi Prabha A, Prem Kumar K, Ganeshkumar S, Govindaraju M (2012b) Synthesis of silver nanoparticles from Sargassum tenerrimum and screening phytochemicals for its anti-bacterial activity. Nano Biomed Eng 4:12-16. doi:10.5101/nbe.v4i1.p12-16

Lengke MF, Fleet ME, Southam G (2006a) Morphology of gold nanoparticles synthesized by filamentous cyanobacteria from Gold(I)-thiosulfate and Gold(III)-chloride complexes. Langmuir 22:2780-2787. doi:10.1021/la052652c

Lengke MF, Fleet ME, Southam G (2006b) Synthesis of platinum nanoparticles by reaction of filamentous cyanobacteria with Platinum(IV)-chloride complex. Langmuir 22:7318-7323. doi:10.1021/la060873s

Lengke MF, Fleet ME, Southam G (2007a) Biosynthesis of silver nanoparticles by filamentous cyanobacteria from a Silver(I) nitrate complex. Langmuir 23:2694-2699. doi:10.1021/la0613124

Lengke MF, Fleet ME, Southam G (2007b) Synthesis of palladium nanoparticles by reaction of filamentous cyanobacterial biomass with a Palladium(II) chloride complex. Langmuir 23:89828987. doi:10.1021/la7012446

Li Y et al. (2015) Biosynthesis of silver nanoparticles using Euglena gracilis, Euglena intermedia and their extract. IET Nanobiotechnol 9:19-26. doi:10.1049/iet-nbt.2013.0062

Liu B, Xie J, Lee JY, Ting YP, Chen JP (2005) Optimization of high-yield biological synthesis of singlecrystalline gold nanoplates. J Phys Chem B 109:15256-15263. doi:10.1021/jp051449n

Luangpipat T, Beattie IR, Chisti Y, Haverkamp RG (2011) Gold nanoparticles produced in a microalga. J Nanopart Res 13:6439-6445. doi:10.1007/s11051-011-0397-9 
Mahdavi M, Namvar F, Ahmad MB, Mohamad R (2013) Green biosynthesis and characterization of magnetic iron oxide $\left(\mathrm{Fe}_{3} \mathrm{O}_{4}\right)$ nanoparticles using seaweed (Sargassum muticum) aqueous extract. Molecules 18:5954-5964. doi:10.3390/molecules18055954

Mahdieh M, Zolanvari A, Azimee AS, Mahdieh M (2012) Green biosynthesis of silver nanoparticles by Spirulina platensis. Sci Ira F 19:926-929. doi:10.1016/j.scient.2012.01.010

Mata YN, Torres E, Blazquez ML, Ballester A, Gonzalez F, Munoz JA (2009) Gold(III) biosorption and bioreduction with the brown alga Fucus vesiculosus. J Hazard Mater 166:612-618. doi:10.1016/j.jhazmat.2008.11.064

Mohseniazar M, Barin M, Zarredar H, Alizadeh S, Shanehbandi D (2011) Potential of microalgae and lactobacilli in biosynthesis of silver nanoparticles. Biolmpacts 1:149-152. doi:10.5681/bi.2011.020

Momeni S, Nabipour I (2015) A simple green synthesis of palladium nanoparticles with Sargassum alga and their electrocatalytic activities towards hydrogen peroxide. Appl Biochem Biotechnol 176:1937-1949. doi:10.1007/s12010-015-1690-3

MubarakAli D, Gopinath V, Rameshbabu N, Thajuddin N (2012) Synthesis and characterization of CdS nanoparticles using C-phycoerythrin from the marine cyanobacteria. Mater Lett 74:8-11. doi:10.1016/j.matlet.2012.01.026

Nagarajan S, Arumugam Kuppusamy K (2013) Extracellular synthesis of zinc oxide nanoparticles using seaweeds of Gulf of Mannar, India. J Nanobiotechnol 11:39. doi:10.1186/1477-3155-11-39

Ninfa AJ, Ballou DP, Benore M (2010) Fundamental laboratory approches for biochemistry and biotechnology. 2nd edn. Wiley, Hoboken

Pandimurugan R, Thambidurai S (2014) Seaweed-ZnO composite for better antibacterial properties. J Appl Polym Sci 131:40948. doi:10.1002/app.40948

Pantidos N, Horsfall LE (2014) Biological synthesis of metallic nanoparticles by bacteria, fungi and plants. J Nanomed Nanotechnol 5:5. doi:10.4172/2157-7439.1000233

Parial D, Patra HK, Dasgupta AKR, Pal R (2012a) Screening of different algae for green synthesis of gold nanoparticles. Eur J Phycol 47:22-29. doi:10.1080/09670262.2011.653406

Parial D, Patra HK, Roychoudhury P, Dasgupta AK, Pal R (2012b) Gold nanorod production by cyanobacteria - a green chemistry approach. J Appl Phycol 24:55-60. doi:10.1007/s10811-0109645-0

Patel V, Berthold D, Puranik P, Gantar M (2015) Screening of cyanobacteria and microalgae for their ability to synthesize silver nanoparticles with antibacterial activity. Biotechnol Report 5:112-119. doi:10.1016/j.btre.2014.12.001

Rahman A, Ismail A, Jumbianti D, Magdalena S, Sudrajat H (2009) Synthesis of copper oxide nano particles by using Phormidium Cyanobacterium. Indo J Chem 9:355-360.

Rajeshkumar S, Malarkodi C, Gnanajobitha G, Paulkumar K, Vanaja M, Kannan C, Annadurai G (2013) Seaweed-mediated synthesis of gold nanoparticles using Turbinaria conoides and its characterization. J Nanostruct Chem 3:44. doi:10.1186/2193-8865-3-44

Rösken LM, Körsten S, Fischer CB, Schönleber A, van Smaalen S, Geimer S, Wehner S (2014) Timedependent growth of crystalline $\mathrm{Au}^{0}$-nanoparticles in cyanobacteria as self-reproducing bioreactors: 1. Anabaena sp. J Nanopart Res 16:2370. doi:10.1007/s11051-014-2370-x

Satapathy S, Shukla SP, Sandeep KP, Singh AR, Sharma N (2014) Evaluation of the performance of an algal bioreactor for silver nanoparticle production J Appl Phycol 27:285-291 doi:10.1007/s10811-0140311-9

Schröfel A, Kratošová G, Bohunická M, Dobročka E, Vávra I (2011) Biosynthesis of gold nanoparticles using diatoms-silica-gold and EPS-gold bionanocomposite formation. J Nanopart Res 13:32073216. doi:10.1007/s11051-011-0221-6 
Senapati S, Syed A, Moeez S, Kumar A, Ahmad A (2012) Intracellular synthesis of gold nanoparticles using alga Tetraselmis kochinensis. Mater Lett 79:116-118. doi:10.1016/j.matlet.2012.04.009

Sharma B, Purkayastha DD, Hazra S, Gogoi L, Bhattacharjee CR, Ghosh NN, Rout J (2014) Biosynthesis of gold nanoparticles using a freshwater green alga, Prasiola crispa. Mater Lett 116:94-97. doi:10.1016/j.matlet.2013.10.107

Stein JR (1973) Handbook of Phycological methods. Culture methods and growth measurements. Cambridge University Press, Cambridge

Subramaniyam V, Subashchandrabose SR, Thavamani P, Megharaj M, Chen Z, Naidu R (2015) Chlorococcum sp. MM11 - A novel phyco-nanofactory for the synthesis of iron nanoparticles. J Appl Phycol 27:1861-1869. doi:10.1007/s10811-014-0492-2

Xie J, Lee JY, Wang DIC, Ting YP (2007a) Identification of active biomolecules in the high-yield synthesis of single-crystalline gold nanoplates in algal solutions. Small 3:672-682. doi:10.1002/smll.200600612

Xie J, Lee JY, Wang DIC, Ting YP (2007b) Silver nanoplates: From biological to biomimetic synthesis. ACS Nano 1:429-439. doi:10.1021/nn7000883

Yin X, Chen S, Wu A (2010) Green chemistry synthesis of gold nanoparticles using lactic acid as a reducing agent. Micro \& Nano Letters 5:270-273. doi:10.1049/mnl.2010.0117 